\title{
PALLIATIVE CARE FOR CHINESE IMMIGRANTS IN NEW ZEALAND: EXPERIENCES AND PERCEPTIONS
}

\author{
Jin Tian ${ }^{1}$, Shuqiang $\mathrm{An}^{2}$, Wei Yuan ${ }^{3}$
}

\begin{abstract}
Over the past several decades, palliative care has seen tremendous development in Western countries, but there is still inadequate access to palliative care among non-dominant ethnocultural groups. The Chinese have been the largest immigrant group in New Zealand since the $19^{\text {th }}$ century(1). They have unique beliefs and practices around illness, death, dying and filial piety (2). These differ greatly from those in Western cultures and have notable implications for hospice palliative care planning and provision. However, immigrant Chinese community remains a relatively marginalised and under-researched group in palliative care(3-5). This results in limited knowledge about its culture and people among health professionals, as well as the lack of experience in providing terminal care to Chinese immigrants. Through the introduction of New Zealand Palliative Care Strategy and the analysis of Chinese immigrants' difficulties and preferences for palliative care, this aims to increase understanding of how cultural values of Chinese affect their acceptance and decision-making with respect to palliative care so that for efficiently providing palliative care to this ethnic minority group in New Zealand.
\end{abstract}

Keywords: palliative care, Chinese immigrants, perceptions, recommendations

\section{Cuidados paliativos para inmigrantes chinos en Nueva Zelanda: experiencias y percepciones}

Resumen: En las últimas décadas, los cuidados paliativos han experimentado un enorme desarrollo en los países occidentales, pero el acceso a los mismos sigue siendo insuficiente entre los grupos etnoculturales no dominantes. Los chinos son el mayor grupo de inmigrantes en Nueva Zelanda desde el siglo XIX(1). Tienen creencias y prácticas únicas en torno a la enfermedad, la muerte, el morir y la piedad filial(2). Éstas difieren en gran medida de las de las culturas occidentales y tienen notables implicaciones para la planificación y prestación de cuidados paliativos en los hospicios. Sin embargo, la comunidad china inmigrante sigue siendo un grupo relativamente marginado y poco investigado en el ámbito de los cuidados paliativos(3-5). Esto se traduce en un conocimiento limitado sobre su cultura y su población entre los profesionales sanitarios, así como en la falta de experiencia en la prestación de cuidados terminales a los inmigrantes chinos. A través de la introducción de la Estrategia de Cuidados Paliativos de Nueva Zelanda y el análisis de las dificultades y preferencias de los inmigrantes chinos en materia de cuidados paliativos, este ensayo pretende aumentar la comprensión de cómo los valores culturales de los chinos afectan a su aceptación y la toma de decisiones con respecto a los cuidados paliativos para que para proporcionar de manera eficiente los cuidados paliativos a este grupo étnico minoritario en Nueva Zelanda.

Palabras clave: cuidados paliativos, inmigrantes chinos, percepciones, recomendaciones

\section{Cuidados paliativos para imigrantes chineses na Nova Zelândia: experiências e percepçóes}

Resumo: Nas últimas décadas, os cuidados paliativos tem experimentado um enorme desenvolvimento nos países ocidentais mas ainda há acesso inadequado a cuidados paliativos entre grupos étnico-culturais náo dominantes. Os chineses tem sido o maior grupo de imigrantes na Nova Zelândia desde o século XIX(1). Eles tem crenças e práticas singulares em torno de doença, morte, morrer e devoção filial(2). Isso difere grandemente das culturas ocidentais e tem implicações notáveis no planejamento e fornecimento de cuidados paliativos em lares de idosos. Entretanto, a comunidade de imigrantes chineses permanece sendo um grupo relativamente marginalizado e sub-investigado no que diz respeito a cuidados paliativos(3-5). Isso resulta em conhecimento limitado sobre sua cultura e povo entre profissionais da saúde, bem como na falta de experiência em fornecer cuidados terminais a imigrantes chineses. Através da introduçâo da Estratégia de Cuidados Paliativos da Nova Zelândia e a análise das dificuldades e preferências de imigrantes chineses para cuidados paliativos, esse estudo tente aumentar a compreensáo de como valores culturais de chineses afetam sua aceitação e tomada de decisão a respeito de cuidados paliativos, de maneira a eficientemente fornecer cuidados paliativos a esse grupo étnico minoritário na Nova Zelândia.

Palavras chave: cuidados paliativos, imigrantes chineses, percepçóes, recomendações

\footnotetext{
${ }^{1}$ Division of Oncology, Shijiazhuang Ping'an Hospital, Shijiazhuang 050000, China. ORCID: 0000-0002-0257-4302 Correspondence: jtia716@aucklanduni.ac.nz

${ }^{2}$ Division of Surgical Transplantation, No 1 Affiliated Hospital of Xi'an Jiaotong University, Xi'an 710061, China. Division of Renal Medicine, Shijiazhuang Ping'an Hospital, Shijiazhuang 050000, China.

${ }^{3}$ Division of Education and Research, Shijiazhuang Ping'an Hospital, Shijiazhuang 050000, China.
} 


\section{Introduction}

Palliative care, while still a comparatively novel component to modern medical care, is increasingly playing an indispensable role in all medical care systems. Early initiation of appropriate palliative care promotes a life of higher quality with improved symptoms and mood status and less use of undesired invasive or costly therapies(4). Despite the benefits of palliative care, previous studies have indicated hospice and associated palliative care services are under-utilised among Chinese diaspora across the world including New Zealand. A qualitative exploratory study conducted by Frey et al. in 2013 showed that Chinese immigrants prefer to receive acute hospital care rather than the terminal care even in end-oflife situations(5). However, as Payne et al. note, making less use of hospice care services does not mean that those services are not needed(3). Current palliative care literature often portrayed cultural differences and poor language skills between Chinese and the adopted community as significant impediments to access to palliative care, yet understanding the reasons hampering the uptake are unclear. With an ageing Chinese immigrant population who are going to be living and dying with more complex and chronic health conditions, the need for hospice care is only going to become more prominent.

To understand the reasons for the dearth of palliative care services, we have to understand the difficulties they experienced when receiving services. This helps us determine their end-of-life preferences which may have significant implications for palliative care provision for immigrant Chinese patients and their families.

\section{Background}

New Zealand is one of the world's leading destinations for Chinese immigrants. As of the 2018 Census, $4.9 \%$ of New Zealand's population identified as Chinese(1). Though Chinese immigrants have adopted New Zealand as their home, they still value their culture and tradition, particularly in times of crisis. However, culture is not static, but in constant flux. It is affected by migration and integration experience of Chinese diaspora living in New Zealand and effectually evolve into their diverse attitudes and beliefs towards the disease, dying, death and hospice care, which differ greatly from those in New Zealand and also in China $(2,5)$.

Acknowledging this cultural diversity is imperative because, as Ord and Wynaden elaborated, palliative care is holistic care which requires health professionals to be aware of and sensitive to an individual's particular cultural beliefs, values and norms(6). This is further reflected in the vision outlined in the New Zealand Palliative Care Strategy aims to provide culturally accessible palliative care services to all patients and their families in a coordinated manner(7). To achieve this ambitious blueprint, nine actionable strategies has been developed which will be executed over a five-to-ten-year period in order of priority, such as ensuring the accessible hospice services for all population groupings in particularly for the Mãori and Pacific peoples.

New Zealand acknowledges the existence of cultural diversity and understands the importance of culturally safe practices. However, it is never easy preserving harmony in a multicultural society. Looking specifically at traditional Chinese culture and palliative care within New Zealand health care system suggests that Chinese immigrants with hospice care needs might face "dual challenges". For some immigrant Chinese patients and their families, it is already challenging to discuss death or end-of-life care. It can be more difficult to understand Chinese immigrants' physical, psychosocial, and spiritual needs when health care professionals are bearers of Western bioethics and values $(8,9)$. In addition, it is worth mentioning that there are no specific measures and approaches for Chinese cultural barriers in New Zealand Palliative Care strategy. Regrettably, the "highly visible Chinese community" becomes the "forgotten one" in this "Land of Long White Cloud ".

\section{Difficulties}

\subsection{Unfamiliar field}

Seymour et al. found that only a few Chinese participants had heard of the terms "palliative care" and "hospice" (10). Most Chinese partici- 
pants show a preference for hospital admissions rather than hospice admissions because they believed that hospice environment was discouraging and not fit for their needs. Recently, Barwise et al. used secondary analysis of a national survey data and found that Chinese immigrants including those born in the adopted country had less knowledge of palliative care(11).

\subsection{Lingering attitudes and beliefs}

\section{(1) Death taboo}

Death is the biggest taboo in China. Anything associated with death is seen as misfortune(2). They even pay extra for mobile phone number without digit 4 as it sounds like the Chinese word for "death". Similarly, they avoid talking about palliative care. They believe that merely mentioning these words will invoke bad fortune and make the inevitability death closer than it perhaps already is. The silent attitude to the discussion of death and dying leads to misunderstanding about palliative care service in terms of its nature, quality, and inclusiveness(12). For example, Chinese people believe that hospice is associated with imminent death and hospice care embraces the slow wait to death rather than fighting to get better. They prefer to believe that life is inherently better than death. It is, therefore, better to live one more minute rather than forgoing the ghost prematurely. Thus, many Chinese to dismiss palliative care out of hand.

\section{(2) Family-centred care and filial piety}

In Chinese culture, the family is the basic unit of worship, hierarchy, emotional support and economic activity. Individual is a part of the family is an entity that had existed before the individual was born and will continue beyond the individual's life $\operatorname{span}(13)$. The relationship between family members is harmoniously interdependent and the sense of obligation is also great within the Chinese family. It is therefore, any disease suffered by an individual becomes the responsibility of the whole family. Elderly patients wish to be cared for by their children and family members often assume their responsibilities to provide primary care. This entrenched values of filial piety and reverence for our seniors imply that if an old relative affected severe disease and their family members do not try their best to help them recover, then the family have failed to perform their duty.

Filial duty, namely Hsiao, impedes implementation of palliative care among all Asian groups, including Chinese(5). Confucianism and Buddhism, as the main philosophies or religions in Chinese culture, underpinning the moral code and practice for filial piety, requires adult children to take responsibility for their parents' health, safety and general well-being(14). Adult children believe that palliative care would signify a lack of caring on the part of the family, the adoption of hospice care is an unfilial act because it would represent that they were not doing enough.

\subsection{Language difficulties}

Language difficulty is one of the most significant barrier to accessing and using palliative care services for Chinese immigrant patients and their families. This has been found in almost all studies involving the experience of Chinese immigrants(15). The absence of linguistic competency not only leads to the additional psychological stress and discomfort for patients but also can amplify other existing barriers and result in various negative consequences $(5,16)$. Chan and Kayser-Jones found that discussing the issues of death and palliative care can be negatively affected if not using patient's mother tongue(17). Lim et al. conducted a review regarding the unmet needs of Chinese immigrants with cancer. They found that language barrier often led to unmet information needs, which in turn increased the risk of poor cancer outcomes(18).

Another communication conundrum is related to interpretation(19). It is notable that, where there is a translation, there is also the potential for miscommunication or misinterpretation(20). For example, "palliative" is not a word present in the Chinese language; it is translated in several

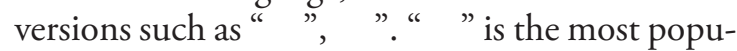
lar one in mainland China, which means "taking away treatment, giving up or indulge in disease" after back translation to English. To culturally sensitive translation is a necessity for improving the use and the quality of palliative care. This is particularly important for the Chinese elders who 
have not been acculturated with Western culture(5). However, there are not enough interpreters and systematic approach to effectively implementing palliative care practice among Chinese immigrants in New Zealand.

\subsection{Insufficiently culturally competent care}

The different cultural system poses challenges to palliative care staffs in providing culturally competent care for Chinse immigrant patients. Kearns and Dyck maintains that the lesser value attached to the knowledge of "others" compared to the value attached to Western medicine has led to barriers to accessing palliative care for the culturally diverse population in New Zealand(21).

Chan and Kayser-Jones concurred that terminally ill Chinese residents in nursing homes encounter many barriers to receive culturally sensitive care even though with an adequate understanding of and engagement with palliative care services(17). Frey et al. carried out a study to explore the effects of culture on the use of palliative care services and found that the absence of shared cultural scripts between service providers and service users prevent Chinese migrants requesting palliative care(5). A study carried out in Australia also found the female Chinese immigrants felt isolated in caring terminally ill family member due to the loss of familiar cultural understanding(22).

\subsection{Insufficient resources and institutional sup- port}

Lacking of specific training to assist health care professionals in understanding the palliative care information that resonates with Chinese immigrants. When working with an unfamiliar culture like Chinese culture, health professionals may be ill-equipped to handle the emotional reactions of consumers and are unable to honour consumers' expectations for care. Meanwhile, they themselves may be weighed down by what information should be communicated to whom and what choices and care should be offered(23).

Another reported barrier is that there is no shared consensus regarding who is supposed to initiate discussions regarding palliative care with patients/ families(23). As it currently stands, opening up such conversations do not appear to fall onto any one individual directly, and so often it is expected that someone in the team will handle them.

\section{Preferences}

\subsection{Place of death}

Previous studies regarding the experience of place of death found that there was a shift in preference from death at home to hospital, and then back again to the home(24-27).

Choosing death in the hospital is influenced by the Chinese superstition that dying at home could bring bad luck to the family(3). With the development of modern science, the influence of this superstition gradually becomes weaker. Obey tradition and choose to die at home is one example.

For overseas Chinese, their memories about their motherland which includes culture and traditions become more vivid and precious as time goes by. "Falling leaves return to their roots", which means everything reverts to its origin, is an important traditional Chinese religious concept. As the home is the place where people live and where one is deeply rooted, dying at home has a particular meaning for the immigrant Chinese(28). Patients' psychological needs, like staying with the family until the very last moment also play a role in choosing to death at home(8).

\subsection{Treatment plan}

(1) Less using advanced directives

Chinese immigrants think to discuss advanced directives and advanced care plan is unpleasant and may beget bad fortune(24). They are unwilling to use advance directives or advance care planning as they think it is unwise to plan for events which have not happened yet(2).

McNamara et al. found that, instead of making living wills, Chinese immigrants preferred to leave decision-making to physicians and their families(26). Lee et al. argues that preference for collective family decision-making and respect for the authority of doctors are two major reasons for above phenomenon(15). However, Jimenez et al. 
pointed out that putting high values on the family determination and fearing to make wrong decisions were tangible obstacles for Chinese participants to use advance care planning or advance directives(26). In addition, Lee et al. found that due to the obligations of filial piety and family reputation, Chinese immigrants were reluctant to initiate the discussion of advance care planning, even though they believed that advance care planning was necessary(15).

Besides, immigrant Chinese patients have some particular considerations related to advance directives and advance care planning, the most prominent one is dying with dignity. Ting and Mok found that Chinese participants would have positive attitudes to advance care planning if they believed the advance care planning could contribute to a dignified death(28).

\section{(2) Seeking to prolong the life}

Chinese culture has a significant influence on the response to terminal illness. They believe that disease is adversity to be overcome, and death is always seen as untimely and unnatural. Therefore, efforts are usually made to maintain hope for the uncertain future. They use a mixture of Traditional Chinese Medicine and Western medicine to prolong life, as well as look to Chinese culture and traditions to provide psychological $\operatorname{support}(8)$.

The responsibility of filial piety is also a major contributor to life-sustaining preference. Children should try their best to provide care and spend money on advanced treatment to help their patients recover from illness. Otherwise, they will be condemned as unfilial or selfish. Likewise, they think that advocating for aggressive interventions is their obligations, irrespective of their parents' opinions. Also, Chinese individuals stress the need to prepare for the next life, which can be demonstrated by the provision of artificial hydration and nutrition.

\section{(3) Less asking for pain relive}

All hospice patients want to be free from pain and regard this as the most critical component of good death, the Chinese immigrant patients are not the exception. The different thing is that they are less likely to request pain relief treatments than local European patients(29). Bearing pain is regarded as a positive characteristic in Chinese eye, and they are used to keeping the pain private. Using pain relief medications are a sign of weak nature. Particularly, opioid pain relievers are less accepted by the Chinese as it has linked to two Chinese Opium Wars. Moreover, immigrant Chinese grow up in China where has the world's strictest controls on drugs, making them reluctant to use opioid medication due to the fear of side effects and addiction(30).

(4) Disclosing sensitive information in subtle ways

Feser \& Bernard found that Chinese patients want to be informed of their diagnosis and(31). However, Chinese families usually believe that it is not suitable for physicians to tell the terminal illness to patients at the time of diagnosis. They think that disclosing a terminal diagnosis is a harmful and merciless act, whereas "keeping the secret" is a benevolent act that provides support to the patients(32). Indeed, in China, the physician always informs families instead of patients.

However, this does not mean that they would like patients to remain ignorant of their serious situation. McGrath et al. suggest that families tend to disclose sensitive information in more subtle ways (24). They use gradual and nuanced approaches, such as facial expressions and body languages, to convey information to patients. Families think that doing in such a way can give patients time to warm up and saves them from additional psychological distress(33).

\section{Discussion}

5.1 Stereotypes of Chinese immigrants and health professionals' Cultural competency

Compared to native Europeans, it is doubly difficult for Chinese immigrants to uptake and thus benefit from hospice palliative care because not only are they handicapped by culture but also by limited palliative care awareness, stigma and stereotypical assumptions. Some health staffs do not function as gatekeepers as they still make cultural 
presumptions regarding preferences in the utilisation of palliative care based on the attitude that "they will not use it anyway".

While it is widely acknowledged that culture plays a subtle role in low rates of palliative care utilisation by Chinese immigrants, it should not be used as a scapegoat. Every Chinese is different, and the stereotype that Chinese patients do not want to discuss palliative care is perceived as a barrier to access to palliative care. While I acknowledge that culture plays a subtle role in the poor uptake of palliative care, it should not be used as a scapegoat. Sometimes Chinese immigrants may be just "unfamiliar" with palliative care or "unaware" of the benefits of palliative care. From this point, what health professionals need is information giving rather than decision making based on assumptions like "Chinese patients will be...." .

Health professionals need some time and space to reflect on their own thoughts and feelings about hospice care, death and anticipatory loss, so that they can identify their interpersonal and cultural biases and not let them hurt others accidentally or intentionally when talking about or dealing with culturally sensitive issues. Considering this situation, it is vital to provide training on hospice and palliative care for palliative care providers, as well as conduct palliative care education in a cultrally approcite approach and format preferably by Chinese health professionals immigrant Chinese community. Furthermore, to ensure the continuity of palliative care, take Chinese cultural values on health and end-of-life care into consideration, hence incorporating the fundamental principles of hospice care including cultural concerns, treatment choice, site of care, and communication(34). Such culturally appreciated programmes are more likely to equip immigrant Chinese patients and their families with the knowledge and the confidence to actively participate in palliative care and produce possibly better outcomes for them $(5,35)$.

\subsection{Autonomy, family determination and truth- telling}

Western countries respect for individual autonomy, but there is a different picture in China, where the concept of self is enmeshed within family networks. Individual autonomy needs family determination, which means individuals are supposed to make their decisions and actions harmoniously in consultation with the family. Most studies have identified that Chinese patients' preference for a passive role in the decision-making process $(3,32)$. Some people worried about that over-reliance on collective family determination may hinder patients' self-determination in healthcare decisions and thus could negatively affect the validity of advanced directives(15). However, in reality, the family determination could be classified into three levels, including a) the family participates in decision-making with the patient; b) the patient requests the family to involve in decision-making, and c) the family makes decisions alone despite patient's wish to be involved. Only the last level, also known as "paternalistic approach", excludes the patients and violates their autonomy. Sensitive information is kept within the subgroups of the family to protect other family members from great psychological distress that disclosure may cause.

While family determination seems to be morally and culturally reasonable, it makes physicians face a conflict of obligations, putting them at the ethical centre of the storm. The most common confusion is that, who owns the truth when the family asks for withholding the sensitive information? Some measures can be used to solve this dilemma. Firstly, spending time in understanding the cultural issues of clients. Secondly, reaching an understanding of what patients want to know and disclosing the information with sensitivity (e.g., not using words like death, fatal). Thirdly, using an incremental method to deal with requests for non-disclosure. Fourthly, continuous to work with the family, especially when important decisions should be made. Last but not least, remembering that different perspective on autonomy among the Chinese cannot justify non-disclosure to the patient if he or she wants to know(30). After all, it is the patients but not their families or the physicians who eventually possess the right to decide how he or she wants to perform autonomy related to disease(34).

5.3 Incorporate Chinese cultural values into the national strategy 
It is regrettable that there is no specific model or strategy in New Zealand Palliative Care Strategy to facilitate palliative care for the Chinese immigrant who choose Aotearoa as their adopted country. Chinese populations commonly have a wide range health care practices and beliefs surrounding terminal and supportive health care. Palliative care services through hospices or primary care general practices thus supply a "Chinese meets West" platform of health care as Chinese populations have little choice but to engage with Western-health based professionals and practices. Exploring the difficulties and preferences regarding palliative care is a chance for further communication, education and understanding to address inadequacy of awareness and misunderstandings about palliative care, as well as promote hospice services utilisation. There is thus a clear requirement to stress the requirement for integrating an all-around health strategy through the evidencebased understanding within hospice care and the cultural lens of Chinese such as death taboo, filial piety, collectivism, suffering and burden, the role of family in end-of-life care.

\section{Conclusion}

Chinese immigrants in New Zealand do not fully benefit from hospice and associated palliative care services as presently available. In part this is because of Chinese diverse cultural beliefs about hospice and palliative care services, and partly because of current services that are culturally orientated to European-based population. It is therefore imperative to develop more educational programmes targeting both Chinese immigrants. More important, heath care providers should recognise and understand the critical role Chinese culture plays in shaping attitudes, preferences and decisions regarding palliative care. We have to consider the diverse Chinese cultural values and practice surrounding death, dying and end-of-life care and try our best to offer tailored culturally appropriate information and knowledge on hospice care to everyone to ensure they have a say in their end-of-life care and to make Aotearoa a better place to live, and to die.

\section{References}

1. Statistics New Zealand. Population projection tables. Wellington (NZ): New Zealand Government; 2013.

2. Bowman KW, Singer PA. Chinese seniors' perspectives on end-of-life decisions. Soc Sci Med 2001 Aug; 53(4): $455-464$. DOI: 10.1016/s0277-9536(00)00348-8. PMID: 11459396.

3. Payne S, Chapman A, Holloway M, Seymour JE, Chau R. Chinese community views: Promoting cultural competence in palliative care. J Palliat Care. 2005; 21(2): 111-116.

4. Olson DP, Windish DM. Communication discrepancies between physicians and hospitalized patients. Arch Intern Med 2010; 170(15): 1302-1307. DOI: 10.1001/archinternmed.2010.239

5. Frey R, Gott M, Raphael D, et al. 'Where do I go from here'? A cultural perspective on challenges to the use of hospice services. Health Soc Care Community 2013; 21(5): 519-529. DOI:10.1111/hsc.12038

6. Orb A, Wynaden D. Cross-cultural communication and health care practice. Aust J Holist Nurs. 2001; 8(2): 31-38.

7. Ministry of Health. Ministry of Health. Wellington (NZ); 2001.

8. Gott M, Frey R, Robinson J, et al. The nature of, and reasons for, 'inappropriate' hospitalisations among patients with palliative care needs: a qualitative exploration of the views of generalist palliative care providers. Palliat Med 2013; 27(8): 747-756. DOI: 10.1177/0269216312469263

9. Fried, O. 'Many ways of caring': The Central Australian Palliative Care Paintings Project. Progress in Palliative Care 1999; 7(3): 116-119.

10. Seymour J, Payne S, Chapman A, Holloway M. Hospice or home? Expectations of end-of-life care among white and Chinese older people in the UK. Sociol Health Illn 2007; 29(6): 872-890. DOI: 10.1111/j.1467-9566.2007.01045.x

11. Barwise A, Cheville A, Wieland ML, Gajic O, Greenberg-Worisek AJ. Perceived knowledge of palliative care among immigrants to the United States: a secondary data analysis from the Health Information National Trends Survey. Ann Palliat Med. 2019; 8(4): 451-461. DOI: 10.21037/apm.2019.02.06

12. Wei L, Walters J, Guo Q, Fetherston C, O’Connor M. Meaningful and culturally appropriate palliative care for Chinese immigrants with a terminal condition: a qualitative systematic review protocol. JBI Database System Rev Implement Rep 2019 Dec; 17(12): 2499-2505. DOI: 10.11124/JBISRIR-2017-003867. PMID: 31135655. 
Palliative care for Chinese immigrants in New Zealand: experiences and perceptions - Jin Tian, Shuqiang An, Wei Yuan

13. McNamara B, Martin K, Waddell C, Yuen K. Palliative care in a multicultural society: perceptions of health care professionals. Palliat Med 1997; 11(5): 359-367. DOI: 10.1177/026921639701100505

14. Cheng HWB. Advance Care Planning in Chinese Seniors: Cultural Perspectives. Journal of Palliative Care 2018; 33(4), 242-246. DOI: https://doi.org/10.1177/0825859718763644

15. Lee MC, Hinderer KA, Alexander CS. What Matters Most at the End-of-Life for Chinese Americans? Gerontol Geriatr Med 2018; 4: 2333721418778195. DOI: 10.1177/2333721418778195

16. Kagawa-Singer M, Blackhall LJ. Negotiating cross-cultural issues at the end of life: "You got to go where he lives". JAMA. 2001; 286(23): 2993-3001. DOI: 10.1001/jama.286.23.2993

17. Chan J, Kayser-Jones J. The experience of dying for Chinese nursing home residents: cultural considerations. J Gerontol Nurs 2005; 31(8): 26-53. DOI: 10.3928/0098-9134-20050801-11

18. Lim BT, Butow P, Mills J, Miller A, Goldstein D. Information needs of the Chinese community affected by cancer: A systematic review. Psychooncology 2017; 26(10): 1433-1443. DOI: 10.1002/pon.4347

19. Sun A, Bui Q, Tsoh J, Gildengorin Y, Chan G, Cheng J, et al. Efficacy of a Church-Based, Culturally Tailored Program to Promote Completion of Advance Directives Among Asian Americans. Journal of Immigrant and Minority Health 2017; 19(2): 381-391.

20. Temple B. Crossed wires: interpreters, translators, and bilingual workers in cross-language research. Qual Health Res 2002; 12(6): 844-854. DOI: 10.1177/104973230201200610

21. Dyck I, Kearns R. Transforming the relations of research: towards culturally safe geographies of health and healing. Health \& Place 1995; 1(3): 137-147.

22. Heidenreich MT, Koo FK, White K. The experience of Chinese immigrant women in caring for a terminally ill family member in Australia. Collegian 2014; 21(4): 275-285. DOI: 10.1016/j.colegn.2013.06.002

23. Windsor J. Telling the truth to Asian patients in the hospital setting. New Zealand Medical Journal 2008; 121(1286): 92-99.

24. McGrath P, Holewa H, McGrath Z. Practical problems for Aboriginal palliative care service provision in rural and remote areas: equipment, power and travel issues. Collegian 2007; 14(3): 21-26. DOI: 10.1016/s1322-7696(08)60561-2

25. Seymour J, Payne S, Chapman A, Holloway M. Hospice or home? Expectations of end-of-life care among white and Chinese older people in the UK. Sociol Health Illn 2007; 29(6): 872-890. DOI: 10.1111/j.1467-9566.2007.01045.x

26. Hsu CY, O'Connor M, Lee S. Understandings of death and dying for people of Chinese origin. Death Stud 2009; 33(2): 153-174. DOI: $10.1080 / 07481180802440431$

27. Lou C, Lou K, Ridley J. Exploring the meaning of dignity at end of life for Chinese Canadians caregivers: A qualitative cross-cultural study. Palliative Medicine 2021; 35(1): 142-150. DOI: 10.1177/0269216320956809

28. Ting FH, Mok E. Advance directives and life-sustaining treatment: attitudes of Hong Kong Chinese elders with chronic disease. Hong Kong Med J 2011; 17(2): 105-111.

29. Kao, Yee-Hsin \& Chiang, Jui-Kun. Effect of hospice care on quality indicators of end-of-life care among patients with liver cancer: A national longitudinal population-based study in Taiwan 2000-2011. BMC Palliative Care 2015; 14(39): 10.

30. Wong EM, Chan SW. The pain experience and beliefs of Chinese patients who have sustained a traumatic limb fracture. Int Emerg Nurs 2008; 16(2): 80-87. DOI: 10.1016/j.ienj.2008.02.002

31. Feser L, Bon Bernard C. Enhancing cultural competence in palliative care: perspective of an elderly Chinese community in Calgary. J Palliat Care 2003; 19(2): 133-139.

32. Tse CY, Chong A, Fok SY. Breaking bad news: a Chinese perspective. Palliat Med 2003; 17(4): 339-343. DOI: 10.1191/0269216303pm751oa

33. McCabe MS, Wood WA, Goldberg RM. When the family requests withholding the diagnosis: who owns the truth?. $J$ Oncol Pract 2010; 6(2): 94-96. DOI: 10.1200/JOP.091086

34. Sarafis P, Tsounis A, Malliarou M, Lahana E. Disclosing the truth: a dilemma between instilling hope and respecting patient autonomy in everyday clinical practice. Glob J Health Sci 2013; 6(2): 128-137. Published 2013 Dec 20. DOI:10.5539/ghhs.v6n2p128

35. International Association for Hospice \& Palliative Care. Principles of Palliative Care. [cited 2019]; Available from: https:// hospicecare.com/what-we-do/publications/getting-started/6-principles-of-palliative-care.

Received: May 24, 2021

Accepted: July 15, 2021 